\title{
Probability of Osteoporotic Vertebral Fractures Assessment Based on DXA Measurements and Finite Element Simulation
}

\author{
Enrique López¹, Elena Ibarz², Antonio Herrera ${ }^{3,4,5}$, Jesús Mateo 3,4,5, \\ Antonio Lobo-Escolar ${ }^{3,4,5}$, Sergio Puértolas², Luis Gracia ${ }^{2 *}$ \\ ${ }^{1}$ Department of Design and Manufacturing Engineering, University of Zaragoza, Zaragoza, Spain \\ ${ }^{2}$ Department of Mechanical Engineering, University of Zaragoza, Zaragoza, Spain \\ ${ }^{3}$ Department of Surgery, University of Zaragoza, Zaragoza, Spain \\ ${ }^{4}$ Department of Orthopaedic Surgery and Traumatology, Miguel Servet University Hospital, Zaragoza, Spain \\ ${ }^{5}$ Aragón Health Sciences Institute, Zaragoza, Spain \\ Email: elopezc@unizar.es, eibarz@unizar.es, aherrera@salud.aragon.es, jmateoa@ono.com, \\ aloboescolar@yahoo.es, spb@unizar.es,
}

Received 10 March 2014; revised 29 April 2014; accepted 14 May 2014

Copyright (C) 2014 by authors and Scientific Research Publishing Inc.

This work is licensed under the Creative Commons Attribution International License (CC BY).

http://creativecommons.org/licenses/by/4.0/

c) (7) Open Access

\begin{abstract}
Osteoporotic vertebral fractures represent major cause of disability, loss of quality of life and even mortality among the elderly population. Decisions on drug therapy are based on the assessment of risk factors for fracture, from bone mineral density measurements. The combination of biomechanical models with clinical studies could better estimate bone strength and support the specialists in their decision. A model to assess the probability of fracture, based on the Damage and Fracture Mechanics has been developed, evaluating the mechanical magnitudes involved in the fracture process from clinical bone mineral density measurements. The model is intended for simulating the degenerative process in the skeleton, with the consequent lost of bone mass and hence the decrease of its mechanical resistance which enables the fracture due to different traumatisms. Clinical studies were chosen, both in non-treatment conditions and receiving drug therapy, and fitted to specific patients according their actual bone mineral density measures. The predictive model is applied in a finite element simulation of the lumbar spine. The fracture zone would be determined according loading scenario (fall, impact, accidental loads, etc.), using the mechanical properties of bone obtained from the evolutionary model corresponding to the considered time. Bone mineral density evolution in untreated patients and in those under different
\end{abstract}

*Corresponding author.

How to cite this paper: López, E., Ibarz, E., Herrera, A., Mateo, J., Lobo-Escolar, A., Puértolas, S. and Gracia, L. (2014) Probability of Osteoporotic Vertebral Fractures Assessment Based on DXA Measurements and Finite Element Simulation. Advances in Bioscience and Biotechnology, 5, 527-545. http://dx.doi.org/10.4236/abb.2014.56063 
treatments was analyzed. Evolutionary curves of fracture probability were obtained from the evolution of mechanical damage. The evolutionary curve of the untreated group of patients presented a marked increase of the fracture probability, while the curves of patients under drug treatment showed variable decreased risks, depending on the therapy type. The finite element model allowed obtaining detailed maps of damage and fracture probability, identifying high-risk local zones at vertebral body, which are the usual localization of osteoporotic vertebral fractures. The developed model is suitable for being used in individualized cases. The model might better identify at-risk individuals in early stages of osteoporosis and might be helpful for treatment decisions.

\title{
Keywords
}

\author{
Osteoporosis, Osteoporotic Vertebral Fracture, Predictive Model, Finite Elements, Fracture Risk, \\ Fracture Probability
}

\section{Background}

Currently, osteoporotic fractures represent major cause of disability, loss of quality of life and even death among the elderly population [1]. Osteoporosis is caused by a skeletal involution linked to aging, which is more prevalent in women: the lifetime risk for a fragility fracture at the age of 50 lies within the range of $40 \%$ in women [2].

Vertebral fracture is the most common osteoporotic fracture, being more prevalent in women than in men [3] [4], leading to back pain, kyphosis and severe functional and vital impact in 30\% - 50\% of patients [5] [6].

Underdiagnosis of osteoporotic vertebral fracture is common for the lack of complementary tests in older women who visit the doctor complaining of back pain and sometimes because the symptomatology of the first fracture is not evident [7] [8].

Different publications estimate that only $40 \%$ of fractures are diagnosed [8] [9]; other assessments estimate that only 5\% - 20\% of these vertebral fractures are diagnosed in primary care [10]. The first vertebral fracture is a factor of high risk of new fractures, localized in another vertebra or other areas of skeleton [11]-[15], leading to so-called fracture cascade [16], when new fractures occur in the spine.

Decisions on drug therapy in osteoporotic patients without previous fractures are mainly based on the analysis of risk factors which predispose to fracture. A risk assessment tool called FRAX ${ }^{\circledR}$ (Fracture Risk Assessment Tool) has been developed by the World Health Organization (WHO) for this purpose [17]-[20]. The risk of major osteoporotic fractures (hip, vertebrae, humerus and wrist), or specifically hip fracture over the next 10 years can be estimated with the FRAX ${ }^{\circledR}$ tool. The probability of fracture is calculated on the basis of age, body mass index and several dichotomized variables (previous fracture, smoking, rheumatoid arthritis, etc.). Optionally, Bone Mineral Density (BMD) of the femoral neck can be included for risk calculation. Other studies have questioned the effectiveness of FRAX ${ }^{\circledR}$ as a tool for predicting fracture risk [21] [22].

Several previous surveys have assessed the risk of fracture using various methodologies mostly based on BMD measurements [23] [24]. BMD measurements have also been used for determining the mechanical strength [25] or to develop statistical models for predicting the risk of fracture [26]. Another study used morphological measurements of the femoral head and neck to determine the risk of fracture [27].

In the field of Finite Element (FE) simulation, different models were used for predicting bone strength or fracture risk at different ages. So, Lee [28] presents a micromechanical model of bone behavior, which is difficult to extrapolate to the scale required to get realistic predictions. Boccacio, Zhang [29] [30] develop more advanced macro-mechanical models, analyzing a complete functional unit of the spine in terms of mechanical behavior depending on bone density. MacNeil [31] builds a 2D model in the sagittal plane, using bone geometry and BMD measurements obtained from radiographs and Dual-energy X-ray Absorptiometry (DXA), calculating the stiffness in terms of patient's age. For proximal femoral fractures, Kaneko [32] develops a model based on imaging techniques, establishing a statistical correlation between the prediction of bone strength and the risk of osteoporotic fracture. A different methodology is applied by Bryan [33], who suggests a parametric model incorporating both the geometry and the properties of bone. A similar methodology is used by Bessho [34], with a parametric analysis concerning load and support conditions. Some authors have begun to incorporate yield crite- 
ria for fracture risk prediction, as Derikx [35], who applies the Drucker-Prager criterion on a model made from Quantitative Computed Tomography (QCT), with asymmetric yielding in tension and compression. In a similar way, Tellache [36] applies an anisotropic yield criterion on a model constructed from Computed Tomography (CT) for predicting fracture risk. With a different approach, Amin [37] performs a comparative analysis of fracture risk predictions based on BMD measurements against those ones obtained from an FE model developed from QCT. Finally, on the matter of drug treatments, Keaveny [38] analyzes the influence on bone strength of Parathyroid Hormone (PTH) and alendronate, using a FE model developed from QCT scans of osteoporotic patients.

Currently, the most popular clinical tool for fracture risk assessment is FRAX ${ }^{\circledR}$, which doesn’t consider bone strength as a relevant magnitude. All the aforementioned computational methods use clinical or mechanical magnitudes related to bone fracture in an independent way, without considering their mutual influence as it actually happens.

In view of the current models limitations, we have developed a model for predicting the risk of osteoporotic vertebral fractures based on the Damage Mechanics and Fracture Mechanics. The model is incorporated into a finite element code to simulate the damage evolution over time. Thus, we will estimate the probability of vertebral fracture in the mid and long terms. BMD measurements, from DXA scans, will be incorporated into the model in order to fit it to clinical conditions. The model is not intended for simulating the bone fracture, but to predict the degenerative process in the skeleton, with the consequent lost of bone mass and hence the decrease of its mechanical resistance which enables the fracture due to different traumatisms.

\section{Methods}

In order to develop a predictive model which takes into account the mechanical parameters involved in the fracture process, a correlation between these magnitudes and those ones measured in clinical terms is firstly required. To this effect, Carter and Hayes [39] established a direct relationship between Young's modulus, E, and bone apparent density, $\rho$, for low strain rates $(0.01)$ :

$$
E=2875 \rho^{3}
$$

On the other hand, the relationship between the BMD value and the apparent density is adjusted, according to experimental results, as:

$$
\rho=\rho_{\max }\left(\frac{B M D}{B M D_{\max }}\right)^{\lambda}
$$

being $\lambda$ a numerical parameter that depends on the sample data. For the present study a value of 0.36 was assigned for $\lambda$ in order to fit the actual data presented in [40].

BMD is the current standard for diagnosis of osteoporosis. Over 100 worldwide published papers assessing lumbar spine BMD evolution, both in natural conditions and in patients under drug therapy were selected for analysis. Among them, two treatments have been selected for the comparative study: risedronate, a biphosphonate, in dosage of $5 \mathrm{mg}$ per day [41] and denosumab, a human monoclonal antibody, in dosage of $60 \mathrm{mg}$ per 6 months [42]. These drugs have proven to be effective, and their BMD evolution curves show the required regularity in the analyzed time period.

Bisphosphonates settle in the bone tissue and its effect persists during some time after its administration, and hence it is completely accepted in the clinical practice the use of intermittent or discontinuous treatments. For the risedronate, several studies with a dosage of $5 \mathrm{mg} /$ day [43] [44] corroborate its effectiveness, decreasing the risk of vertebral fractures in women with osteoporosis, improving even in week dosage the results obtained with alendronate [45].

With respect to the use of denosumab, its action principle deals with the blocking of natural bone resorption. Its effectiveness reducing the fracture risk has been demonstrated in a 5 years study [46], being recommendable its use in women with a high fracture risk.

Regarding the natural history of BMD, the average curve published by Mazess [47] was chosen as a reference. Briefly, the natural curve of BMD linked with age was compared to the curves of BMD in patients treated with bisphosphonates or denosumab.

As the model evaluates the mechanical strength of bone from BMD, an analytical function expressing its 
evolution over time is needed. That function must be obtained from numerical data contained in different studies. Since the standard adjustment techniques do not provide enough accuracy and reliability to be applied to the predictive model, more complex adjustments have been set out to obtain continuous curves of regression. These make it possible to obtain continuous curves for the BMD evolution. The evolution trends of the different selected cases in the study can be extrapolated from those continuous curves, ensuring a consistent behavior. The following adjustments were proposed for the apparent density $\rho$ :

- Polynomial:

$$
\rho=a_{n} t^{n}+a_{n-1} t^{n-1}+\cdots+a_{1} t+a_{0}
$$

- Exponential:

$$
\rho=k\left(1-e^{-\left(a_{n} t^{n}+a_{n-1} 1^{n-1}+\cdots+a_{1} t+a_{0}\right)}\right)
$$

- Exponential asymptotic:

$$
\rho=\rho_{0}+\left(\rho_{l i m}-\rho_{0}\right)\left(1-e^{-\frac{a t}{t_{m}-t}}\right)
$$

These adjustments (Equations (3), (4) and (5)) have been applied to the three examined curves (natural evolution and the two therapies). Several choices have been made during this adjustment: the lowest mean square error, the closest to unity correlation coefficient $R^{2}$, and a 10-year standardized follow-up period with the possibility of extrapolation to longer periods up to 15 years (Figure 1). That extrapolation is intended to be consistent in mathematical terms, independently of the actual duration of the considered study. This condition will permit in the future an easy incorporation of more long term studies when available. Standardization of BMD measurements included in each published paper was required in order to make comparisons among them [48], because de data were obtained from different densitometric equipment depending on the study (Hologic, Lunar and Norland).

The Karganovin's Damage Mechanics model [49] was selected for the simulation of the degenerative process. This model defines the mechanical damage, $D$, as a function of the equivalent strain, $\varepsilon_{c}$ :

$$
D=1-\kappa\left(\varepsilon_{c}\right)^{\gamma}
$$

being:

$$
\varepsilon_{c}=\sqrt{\varepsilon_{I}^{2}+\varepsilon_{I I}^{2}+\varepsilon_{I I I}^{2}-\varepsilon_{I} \varepsilon_{I I}-\varepsilon_{I} \varepsilon_{I I I}-\varepsilon_{I I} \varepsilon_{I I I}}
$$

the equivalent strain, where $\varepsilon_{I}, \varepsilon_{I I}, \varepsilon_{I I I}$ are the principal components of the strain tensor. This mechanical damage leads to a decrease of the bone stiffness, according with the relationship:

$$
D=1-\sqrt{\frac{E}{E_{0}}}
$$

where $E_{0}$ corresponds to the Young's modulus of healthy bone and $E$ is the actual value of Young's modulus of the bone with cumulative mechanical damage. The $\kappa$ and $\gamma$ constants depend on the critical damage value, the critical strain and the deformation threshold, $\varepsilon_{0}$, below which no damage is produced ( $\varepsilon_{c}=\varepsilon_{0}$ implies $D$ $=0)$ :

$$
\gamma=\frac{\ln \left(\frac{1}{1-D_{c r i}}\right)}{\ln \left(\frac{\varepsilon_{0}}{\varepsilon_{c r i}}\right)} \quad \kappa=\frac{1}{\left(\varepsilon_{0}\right)^{\gamma}}
$$

where $\varepsilon_{c r i}$ corresponds to the equivalent strain value that produces the critical damage, $D_{c r i}$. Once the damage model is defined, a relationship between the damage level and the probability of fracture must be set. Obviously several factors are involved in the equation and may difficult the calculations: damage location, amount of 


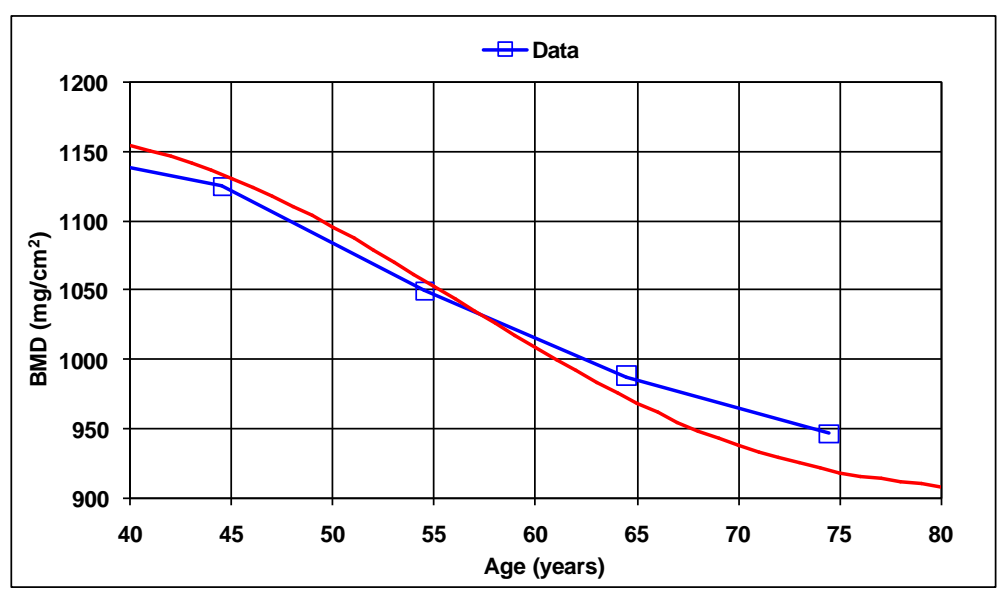

(a)

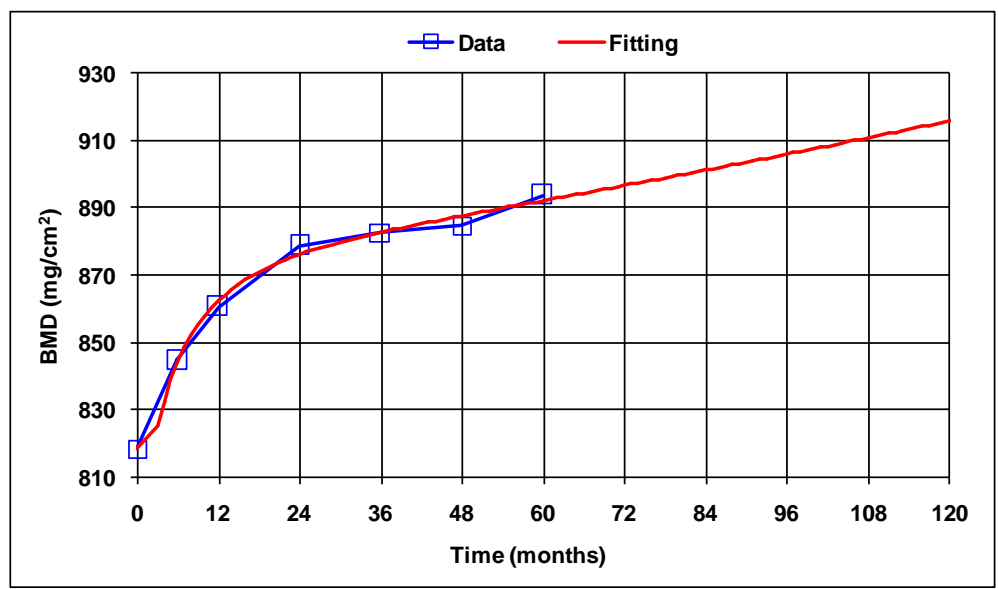

(b)

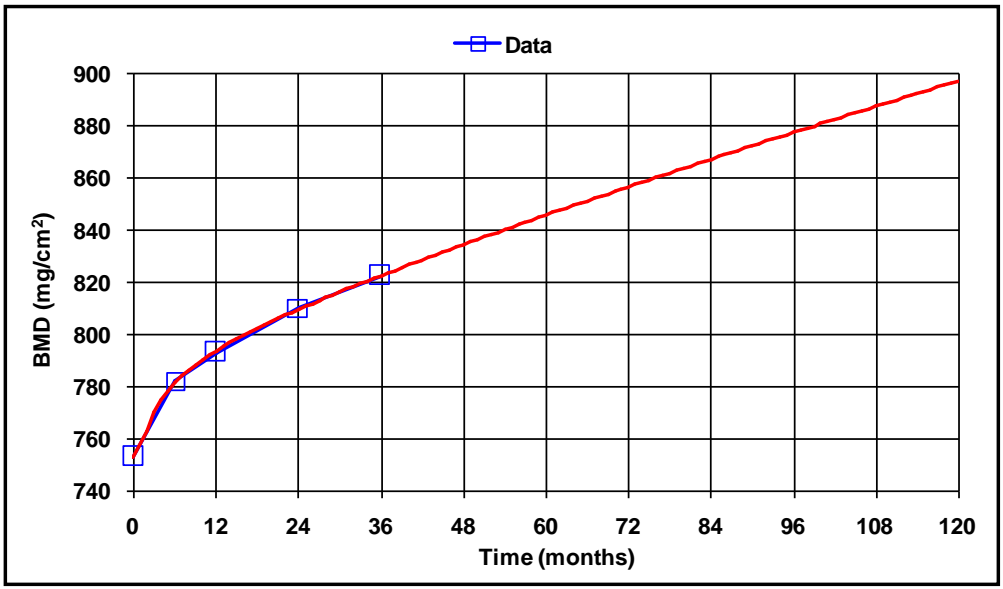

(c)

Figure 1. Fitting of BMD evolutionary curves: (a) Natural evolution $\left(\mathrm{R}^{2}=\right.$ 0.9942); (b) Risedronate (5 mg/day) $\left(\mathrm{R}^{2}=0.995\right)$; (c) Denosumab (60 mg/6 months) $\left(\mathrm{R}^{2}=0.999\right)$.

damage, range and type of load cycles, and so on. However, since osteoporosis is a generalized disease affecting bone mass extensively, and it occurs in older people with little variation in their life habits, a simplified model could be used. In this work, a model of fracture probability based on the law of Paris [50], which explains the 
stable crack growth under monotonic loading, was developed. The number of loading cycles needed to increase damage from the $D_{i}$ value to the $D_{f}$ value was expressed as follows:

$$
N=\frac{1}{\alpha(\Delta \sigma)^{\beta} \gamma^{\beta / 2}\left(\frac{\beta}{2}-1\right)}\left[\left(\frac{1}{\omega D_{i}}\right)^{\frac{\beta}{2}-1}-\left(\frac{1}{\omega D_{f}}\right)^{\frac{\beta}{2}-1}\right]
$$

where $\alpha$ and $\beta$ are material parameters associated with the law of Paris, $\gamma$ is a parameter related to the stress intensity factor defined in Linear Elastic Fracture Mechanics, which depends on geometric aspects and stress distribution, $\Delta \sigma$ is the variation of stress in each loading cycle and $\omega$ is a parameter which relates the mechanical damage to the crack size $a(a=\omega D)$.

By normalizing the probability of fracture, assigning value 1 to critical damage ( $D=D_{c r i}$ ), and value 0 to no damage $(D=0)$, we finally obtain a measure of the probability of fracture as a function of both the number of cycles and the damage:

$$
P(\text { fracture })=1-\frac{N(D)}{N_{\max }}=\left(\frac{D}{D_{c r i}}\right)^{\frac{\beta}{2}-1}
$$

In Equation (11), the magnitude $N_{\max }$ represents the maximum number of load cycles necessary for a mechanical damage equivalent to the critical value, $D_{c r i}$. A value 5 has been given to the $\beta$ coefficient for cortical bone, according to [51], and, in accordance with [49], a critical damage, $D_{c r i}$, of 0.38 and a critical strain, $\varepsilon_{c r i}$, of 0.0174 have been considered, with a strain threshold, $\varepsilon_{0}$, of 0.0015 (no damage is produced by strains below 0.0015).

BMD evolutionary curves for a specific population are basic references and provide only general information. In order to apply the model to specific patients we must consider, in addition to the trend, the reference density value of the patient. According to the law of interpolated natural evolution, the density matching with the age of the patient is given by:

$$
\rho_{N}\left(t_{0}\right) \neq \rho_{0}
$$

being $\rho_{N}\left(t_{0}\right)$ the average density measured in the patient and $\rho_{0}$ the matching value from the reference progression curve, that is, the actual patient's density doesn't necessarily be equal to the value corresponding to the average curve for the considered population. There is an offset that should be added to the reference progression curve of density, providing a translation of the average curve, allowing an adaptation for each individual patient, so:

$$
\rho_{p}^{N}(t)=\rho_{N}(t)+\left[\rho_{0}-\rho_{N}\left(t_{0}\right)\right]
$$

when a drug therapy is applied to the same patient, a similar correction is required because a new offset appears. So, the progression curve for this patient under a treatment would be:

$$
\rho_{p}^{T}(t)=\rho_{T}(t)+\left[\rho_{0}-\rho_{T}\left(t_{0}\right)\right]
$$

In the Equations (12) to (14), the subscripts or superscripts $N$ and $T$ represent natural evolution or evolution with treatment, respectively. All these adjustments provide the estimated BMD value for any type of patient, at any age, and under any prescribed therapy. From this value, mechanical properties of bone can be calculated. It must be noticed that the considered curves represent the mean evolutionary curves for the population, and an individual patient could not follow the curve exactly but in an approximate way.

Densitometric data of the healthy lumbar spine have been taken as the starting point for this study, based on previous published works [47]. In that survey, densitometric data were correlated both with the apparent volumetric density, and with the Young moduli of each of the vertebral zones. Table 1 depicts the BMD, the apparent volumetric density, and the Young moduli correlation corresponding to a healthy vertebra.

From all the previous calculations, an evolutionary algorithm has been implemented (Figure 2), which has been used combined with a finite element model of the lumbar spine containing L4-L5-S1 segments (Figure 3), obtained from a previous complete model of the lumbar spine [52]. L4 and L5 vertebrae and S1 reproduce in a reliable way the anatomy of lumbar spine. 
Table 1. BMD, apparent density and Young's modulus for the data corresponding to the study of [48].

\begin{tabular}{cccc}
\hline Zone & Standard BMD $\mathbf{( m g / \mathbf { c m } ^ { 2 } )}$ & $\begin{array}{c}\text { Apparent volumetric density } \\
\left(\mathbf{g r} / \mathbf{c m}^{\mathbf{3}}\right)\end{array}$ & Young modulus (MPa) \\
\hline Vertebral wall & 1159 & 1.494 & 9593 \\
Outer vertebral endplates & 1159 & 1.494 & 9593 \\
Intermediate vertebral endplates & 610 & 1.186 & 4797 \\
Centre of vertebral endplates & 221 & 0.822 & 1599 \\
Apophyses & 321 & 0.941 & 2398 \\
\hline
\end{tabular}

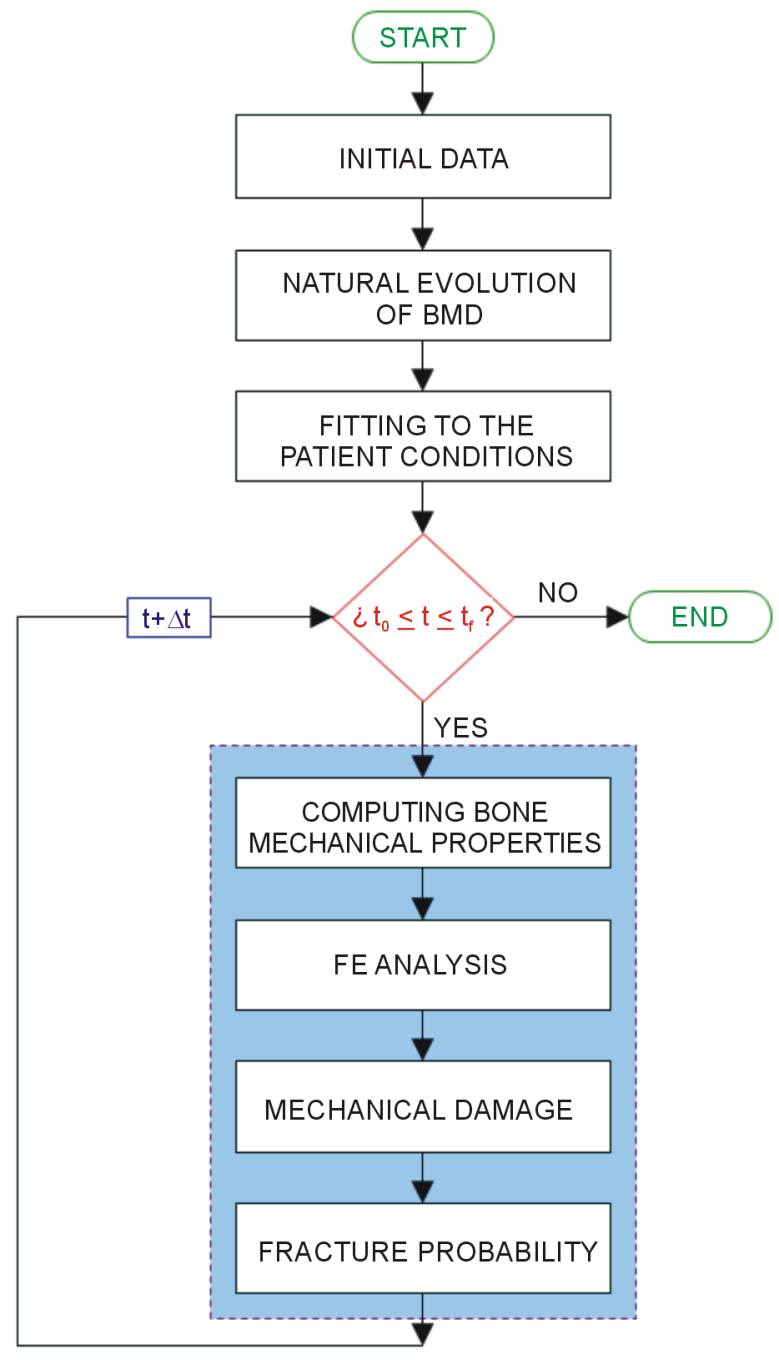

Figure 2. Evolutionary algorithm for the prediction of fracture probability.

The vertebrae were meshed by means of tetrahedral elements with quadratic approximation in the I-deas program [53] as described in [52]. The mesh of the discs is essential for the correct reproduction of the biomechanical behaviour of the lumbar spine; in order to do this, each disc is divided into nucleus pulposus and annulus fibrosus with commonly accepted dimensions [54]. Each part is meshed separately, the nucleus by means of tetrahedra and the annulus by means of hexahedra and prisms with quadratic approximation. Later, nine layers (outer and four double crossed) of concentric fibres are added to the annulus. These layers are modelled by means of tension-only elements, included in the hexahedra matrix, with variable orientation from the most 


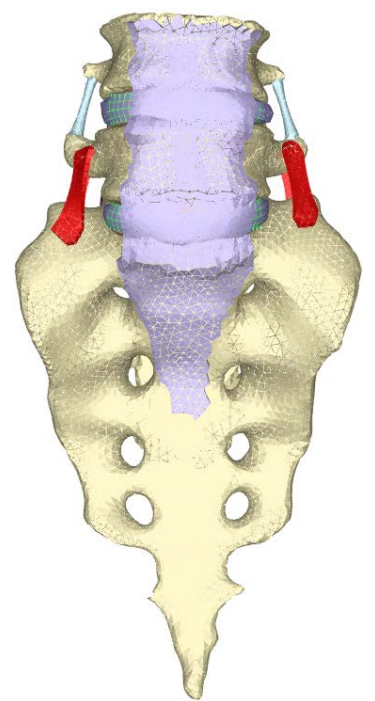

(a)

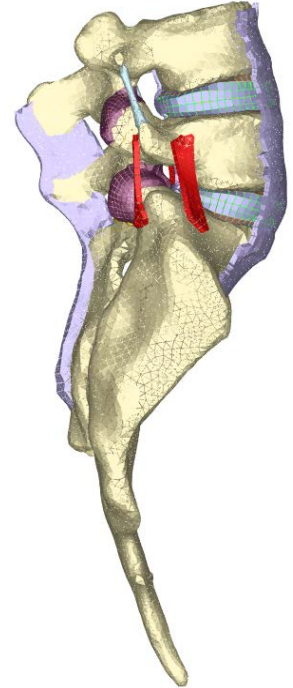

(b)

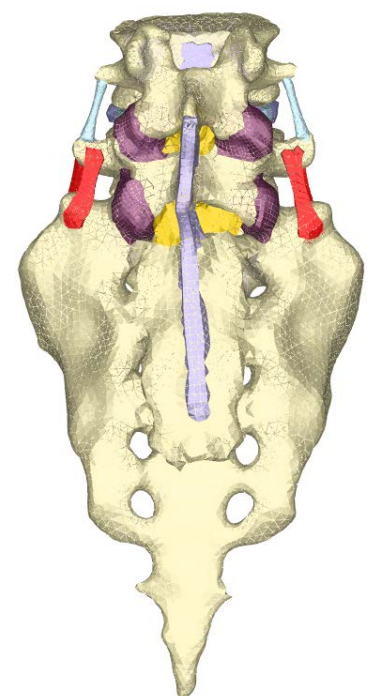

(c)

Figure 3. Complete FE model including vertebrae, discs and ligaments: (a) Frontal view; (b) Lateral view; (c) Dorsal view.

internal to the most external (Figure 4), ranging from $35^{\circ}$ to $80^{\circ}$, respecting at most the anatomical disposition [55].

Finally, the ligaments are modelled by means of tetrahedra and prisms with quadratic approximation; in addition, membrane elements have been used for capsular ligaments. The dimensions of those soft tissues correspond to average anatomical measurements [54] [55] (Figure 3). The number of finite elements for every part is shown in Table 2. The total number of elements of the final mesh, obtained after a sensitivity analysis, is 196,553. To this respect a mesh refinement was performed in order to achieve a convergence towards a minimum of the potential energy, both for the whole model and for each of its components, with a tolerance of $1 \%$ between consecutive meshes.

The bone and ligament properties were taken from the bibliography. Concerning the bone, in [56] it is demonstrated that the centre of the vertebrae is less rigid than in the exterior zone. For this reason the vertebrae are divided into four areas with variable modulus of elasticity (Figure 5). In addition, the corresponding properties are used for the cancellous bone. Material properties are included in Table 2.

The behaviour of the nucleus pulposus, like a non-compressible fluid, was simulated by means of the hyperelastic Mooney-Rivlin model (incompressible) incorporated in the Abaqus version 6.11 materials library [57]. The fibres of the annulus exhibit a non-linear only tension behaviour approximated using different linear models for each layer considering their respective range of deformation [56]. The materials of the matrix and cartilage of the apophyses were simulated as elastic materials. Finally, the different ligaments present non-linear only tension behaviour, included as a bilinear model in the strain range (Table 2) as with most of the reported FEM studies [56] [58].

As boundary conditions displacements in the wings of sacrum have been prevented. As load condition, a compression of $400 \mathrm{~N}$ was considered acting on the upper face of vertebra L4 (Figure 6). That compression simulates the load applied at the lumbar zone as consequence of body weight [59].

The model has been used in predicting the evolution of vertebral fracture probability, by comparing the natural history and the expected evolution under different therapies.

\section{Results}

Firstly, adjustment models were applied both to BMD physiological curve (weighted average from [47]) and the curves of patients under two different therapies: risedronate ( $5 \mathrm{mg}$ per day) and denosumab (60 $\mathrm{mg}$ per 6 months). Figure 1 shows the different evolutionary curves obtained in each case, together with the interpolated curves. Despite an extreme irregularity of some values, the correlation coefficients have been 0.994 (natural evolution), 0.995 and 0.997 , respectively. 

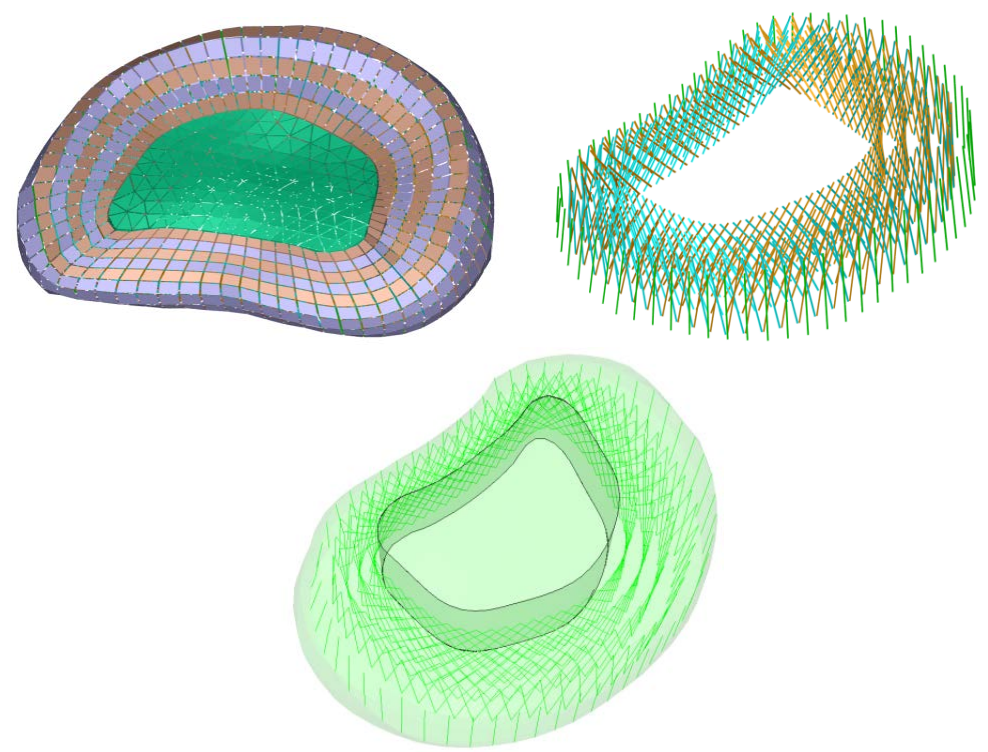

Figure 4. Model of the inter-vertebral disk and its layers of fibres.
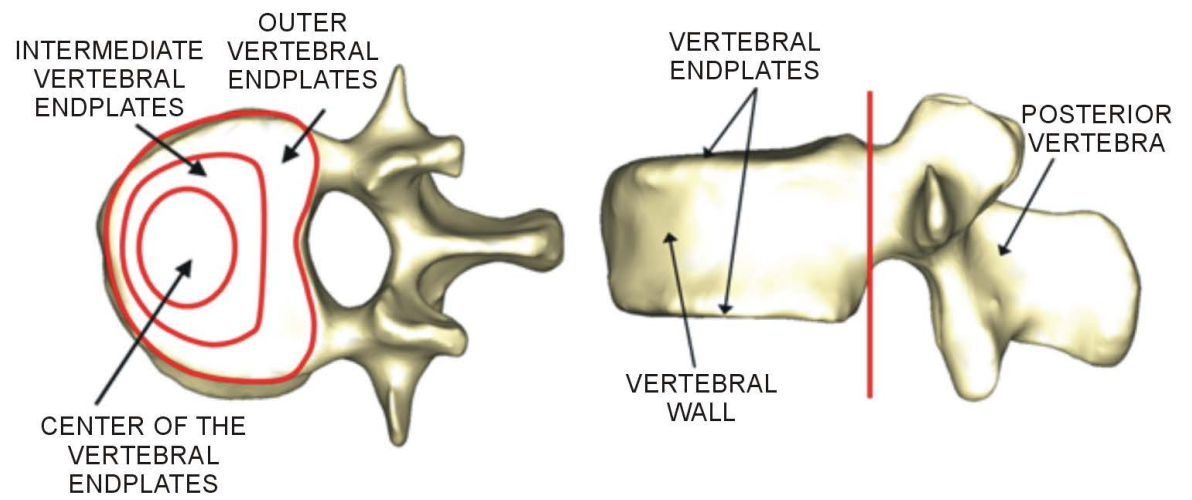

Figure 5. Zones of different elastic properties in the vertebral body.

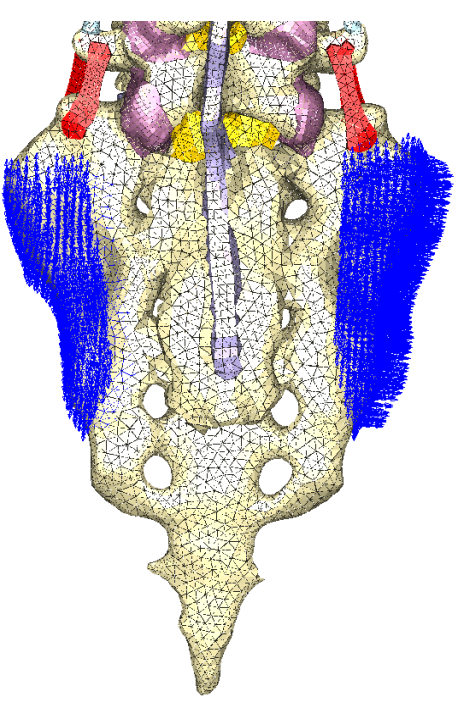

(a)

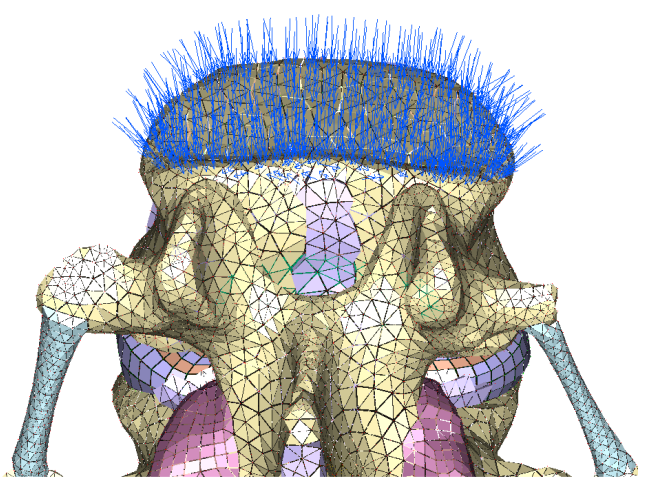

(b)

Figure 6. Boundary conditions: (a) Restrained displacements; (b) Load on L4. 
Table 2. Statistics for the FE model and mechanical properties of materials, according with [52].

\begin{tabular}{|c|c|c|c|c|}
\hline Material & $\begin{array}{l}\text { Young modulus } \\
\text { (MPa) }\end{array}$ & $\begin{array}{c}\text { Poisson } \\
\text { coefficient }\end{array}$ & Element type & $\begin{array}{c}\text { Number of } \\
\text { elements }\end{array}$ \\
\hline Outer vertebral endplates & 12000 & 0.3 & Tetrahedron & 3578 \\
\hline Intermediate vertebral endplates & 6000 & 0.3 & Tetrahedron & 2244 \\
\hline Centre of the vertebral endplates & 2000 & 0.3 & Tetrahedron & 831 \\
\hline Walls of the vertebral body & 12000 & 0.3 & Tetrahedron & 37205 \\
\hline Cancellous bone (inside vertebrae) & 100 & 0.2 & Tetrahedron & 44954 \\
\hline Posterior vertebra & 3000 & 0.3 & Tetrahedron & 47134 \\
\hline Cartilage & 50 & 0.4 & Wedge & 3086 \\
\hline Annulus fibrosus & 4.2 & 0.45 & Hexahedron & 8288 \\
\hline Nucleus pulposus ( $\left.{ }^{*}\right)$ & \multicolumn{2}{|c|}{ Incompressible material } & Tetrahedron & 14410 \\
\hline Annulus fiber layers 1 & 360 & 0.3 & Truss $\left({ }^{* *}\right)$ & 592 \\
\hline Annulus fiber layers 2 & 408 & 0.3 & Truss $\left({ }^{* *}\right)$ & 592 \\
\hline Annulus fiber layers 3 & 455 & 0.3 & Truss $\left({ }^{* *}\right)$ & 592 \\
\hline Annulus fiber layers 4 & 503 & 0.3 & Truss $\left(^{* *}\right)$ & 592 \\
\hline Annulus fiber layers 5 & 550 & 0.3 & Truss $\left({ }^{* *}\right)$ & 296 \\
\hline Ligament & $\begin{array}{l}\text { Young modulus } \\
\text { (MPa) }\end{array}$ & $\begin{array}{c}\text { Transition strain } \\
\text { (\%) }\end{array}$ & Element type & $\begin{array}{c}\text { Number of } \\
\text { elements }\end{array}$ \\
\hline Anterior longitudinal ligament & $\begin{array}{c}7.8 \\
20.0\end{array}$ & 12.0 & Wedge $\left(^{* *}\right)$ & 9046 \\
\hline Posterior longitudinal ligament & $\begin{array}{l}10.0 \\
50.0\end{array}$ & 11.0 & Wedge $\left(^{* *}\right)$ & 3844 \\
\hline Ligamentum flavum & $\begin{array}{l}15.0 \\
19.0\end{array}$ & 6.2 & Tetrahedron $\left(^{* *}\right)$ & 3042 \\
\hline Intertransverse ligament & $\begin{array}{l}10.0 \\
59.0\end{array}$ & 18.0 & Tetrahedron $\left(^{* *}\right)$ & 6678 \\
\hline Capsular ligament & $\begin{array}{c}7.5 \\
33.0\end{array}$ & 25.0 & Membrane $\left(^{* * *}\right)$ & 3220 \\
\hline Interspinous ligament & $\begin{array}{c}8.0 \\
15.0\end{array}$ & 20.0 & Tetrahedron $\left(^{* *}\right)$ & 2856 \\
\hline Supraspinous ligament & $\begin{array}{l}10.0 \\
12.0\end{array}$ & 14.0 & Tetrahedron $\left(^{* *}\right)$ & 2657 \\
\hline Iliolumbar ligament & $\begin{array}{c}7.8 \\
20.0\end{array}$ & 12.0 & Wedge $\left(^{* *}\right)$ & 816 \\
\hline
\end{tabular}

( $\left.{ }^{*}\right) \mathrm{C}_{01}=0.0343 \mathrm{MPa} ; \mathrm{C}_{10}=0.1369 \mathrm{MPa}$. An elastic analysis with Young modulus of $1.0 \mathrm{MPa}$ and Poisson ratio of 0.49 was carried out with similar results and a volume change less than $0.6 \%$. $\left.{ }^{* *}\right)$ Only tension.

Comparisons among various treatments can be drawn regarding different simulations. Figure 7(a) shows BMD evolution curves (average values) under natural conditions and under two therapies (risedronate and denosumab). As can be seen, patients treated with desonumab showed a significant initial increase in bone density, which remained stable until the end of the study period. Risedronate also leads to a remarkable increase in BMD during the first 5 years; a progressive decline after treatment interruption appears (similar to the natural physiological curve). In opposition, the physiological curve was characterized by a substantial and progressive decline in BMD linked to an increased risk of fracture.

Equivalent comparisons can be made with different parameters. Thus, Figure 7(b) shows the evolution of average Young's modulus in untreated patients and in those under drug therapy (risedronate and denosumab). Similar patterns to the observed in BMD curves were obtained, according with the direct relationship between the two parameters. Figure 7(c) shows the evolution of the average equivalent strain in subjects under natural conditions and under the same two therapies (risedronate and denosumab). Contrary to previous trends, as bone stiffness decreases the average deformation shows a significant increase (as it occurs in the natural history of $\mathrm{BMD}$ ). In the case of therapies which preserve BMD, and therefore bone stiffness, the average strain value remained stable or even decreases. Finally, Figure 7(d) illustrates the evolution of average mechanical damage under natural conditions and under the two proposed therapies (risedronate and denosumab). Similar trends to those obtained for strains can be seen. In fact, when the average strain value increases, mechanical damage increases too. 
As a final result, the evolutionary curves of fracture probability were obtained from the evolution of mechanical damage. The estimated probability, according to mechanical damage caused by strains, is calculated for the initial patient's state (Figure 7(e)). Evolutionary curves of fracture probability increase can be obtained by referencing all results to the initial state (Figure 7(f)). As can be seen, the fracture probability shows a marked increase in the natural evolution curve, while the curves of the treated patients show lower degrees of risk, depending on the therapy type.

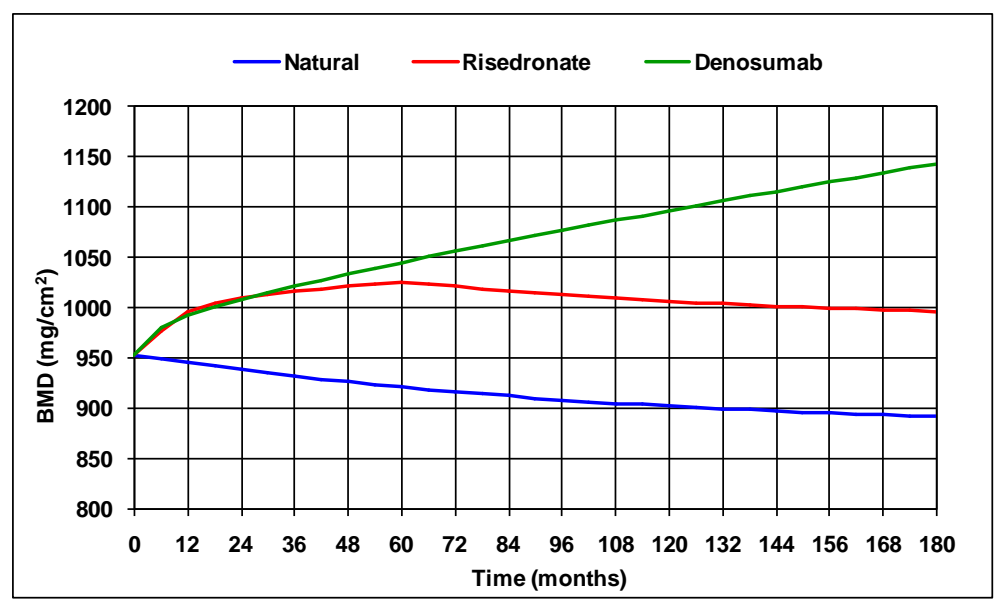

(a)

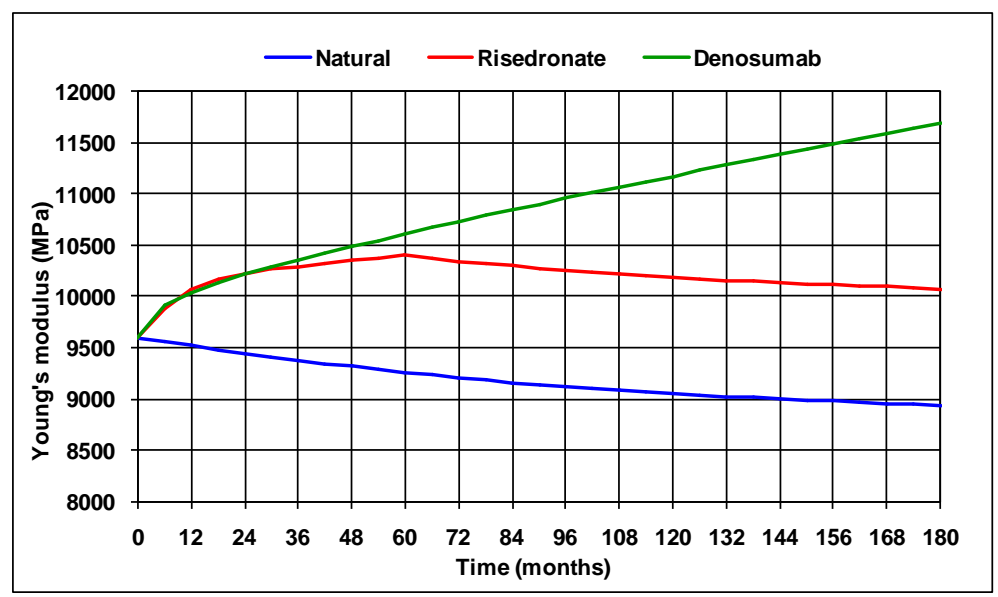

(b)

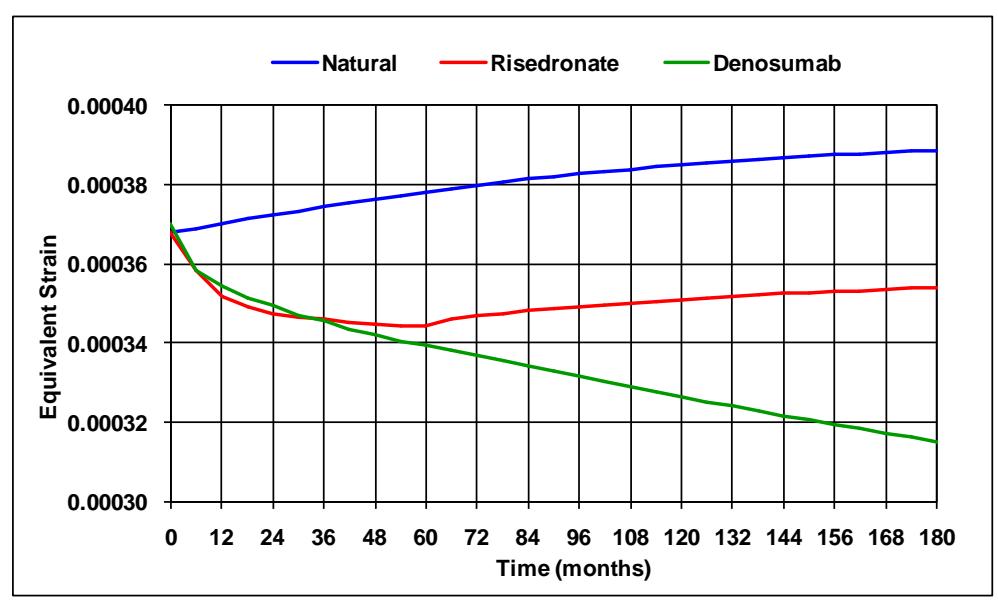

(c) 


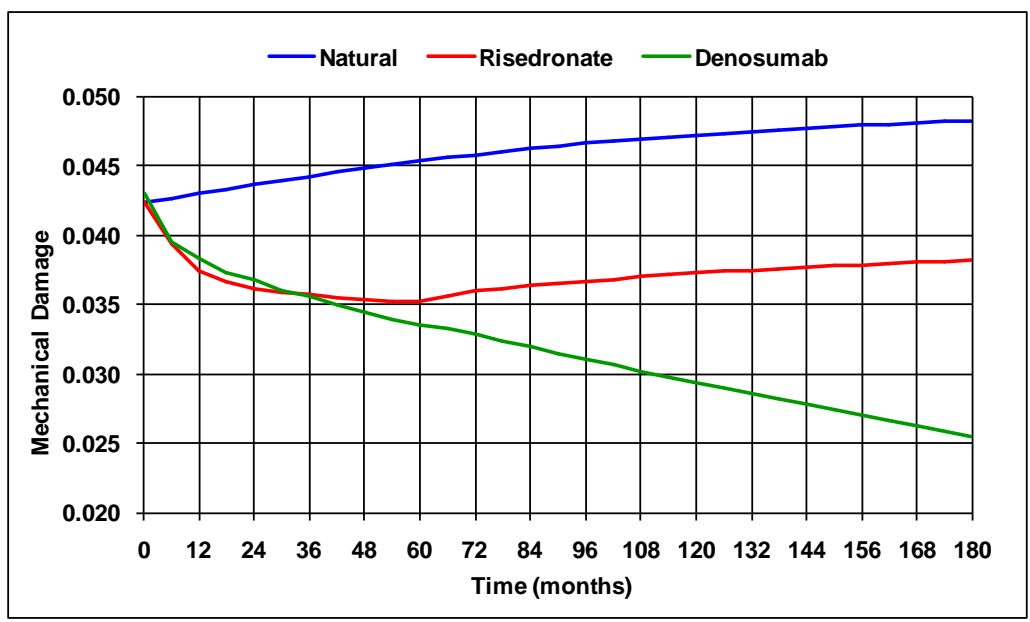

(d)

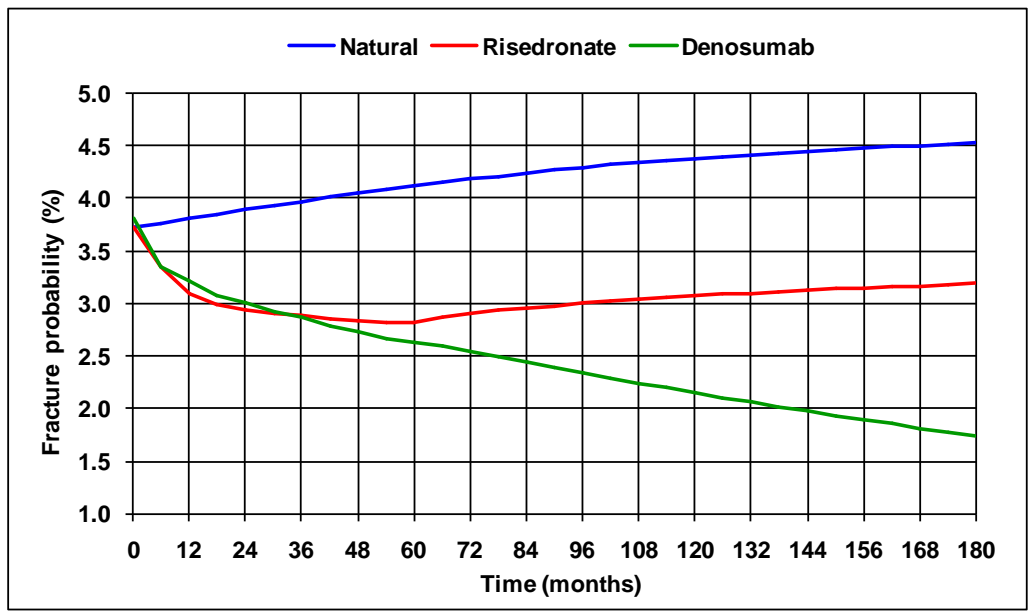

(e)

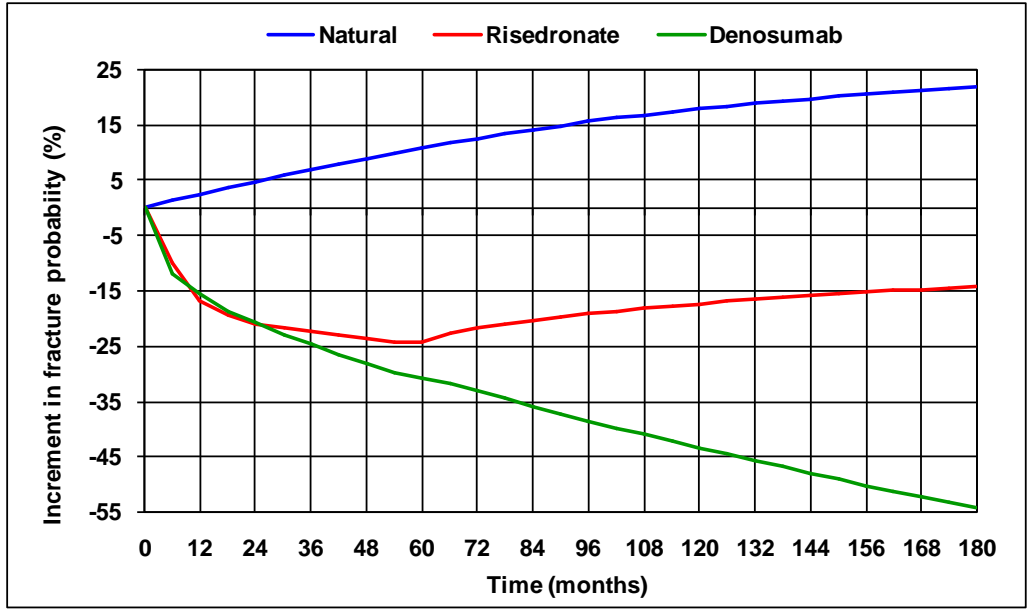

(f)

Figure 7. Evolution of different magnitudes at L5 vertebra: (a) BMD; (b) Average Young's modulus; (c) Average equivalent strain; (d) Average mechanical damage; (e) Evolution of the average fracture probability at L5 in different conditions; (f) Evolution of the average fracture probability increment at L5 in different conditions. 
In addition to previous results, programmed subroutines make it possible to obtain damage and fracture probability maps and to identify high-risk zones of the vertebral body (Figure 8(a) and Figure 8(b), respectively). Vertebral walls and external areas of vertebral end plates are the zones at greatest risk, in coincidence with the typical locations of osteoporotic fractures, characterized by a vertebral crushing due to the collapse of vertebral walls. It must be pointed out that Figure 8 doesn't represent actual fracture zones, but zones with poorer bone mechanical strength due to cumulative damage. The actual fracture zone would be determined according loading scenario (fall, impact, accidental loads, etc.).

\section{Discussion}

The spinal localization of osteoporotic fractures is very common [3] [4] and unfortunately many of these fractures are not diagnosed [7]-[10], so the availability of a tool to inform about of individualized fracture risk is important. It is essential to prevent the first fracture and therefore determine the risk of fracture is a most important aid to the medical doctor for taking made decision to prescribe treatment.

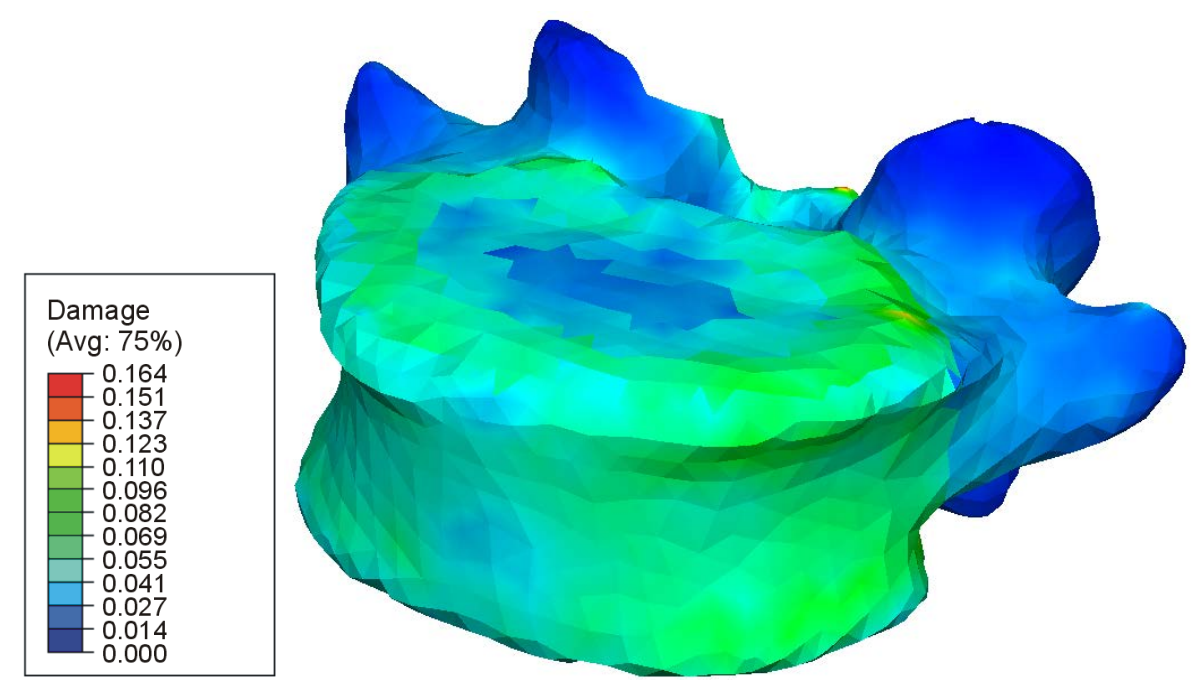

(a)

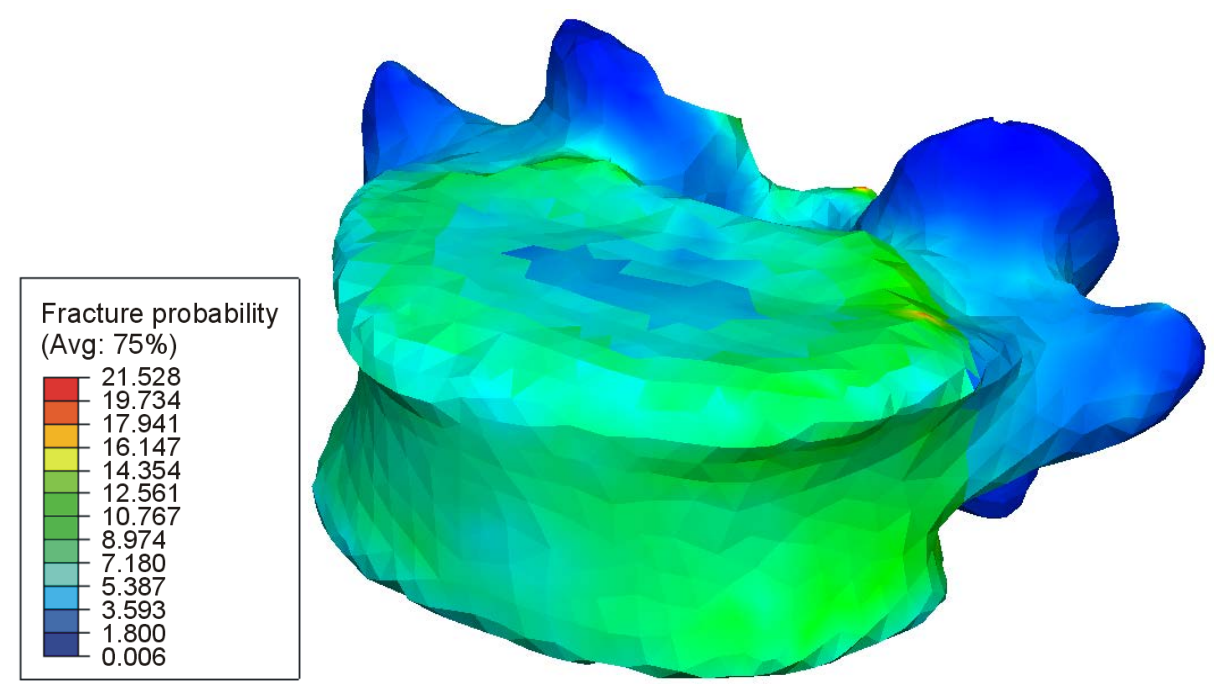

(b)

Figure 8. (a) Mechanical damage map for the studied patient ( $\left.\varepsilon_{0}=0.0015\right)$. Natural evolution (180 months); (b) Fracture probability increase (\%) map for the studied patient ( $\varepsilon_{0}=0.0015$ ). Natural evolution (180 months). 
A novel method for estimating the risk in osteoporotic patients has been developed. Clinical data (DXA measures) and mechanical magnitudes related to bone strength were combined in this tool. The mechanical properties of bone are updated from BMD values obtained from clinical data of untreated patients and in those under different treatments. The model uses Damage and Fracture Mechanics concepts to evaluate the fracture probability in an evolutionary algorithm.

The model can be used in a personalized way from BMD measurements in each case. The model can contribute to the development of diagnostic tools for detection of early stages of osteoporosis. It may also be helpful for treatment decisions in selected patients. Many studies have been carried out, both in the clinical [9]-[19] and the simulation fields [20]-[30]. But a simple and reliable model, useful as a tool for diagnosis and prevention in our daily practice, has not yet been achieved.

There are few studies in the bibliography, besides the tool FRAX ${ }^{\circledR}$, to determine the risk of vertebral fracture. Some authors use clinical data to assess the risk of new fracture after the diagnosis of first vertebral fracture [10]. Other authors have employed logistic regression models based in clinical data and BMD of femoral neck to determine the vertebral fracture risk [60]. Despite the data obtained by the quantitative computed tomography (QCT) were used to develop finite element models, the inconvenience of this technique is the much larger doses of radiation needed for QCT [61]. Other authors therefore employed human cadaveric specimens to obtain data by QCT under different loads to develop the prediction model [62] [63].

Several predictive models can be found in the literature, but statistical models are currently the most reliable [9]-[12], regardless of mechanical issues involving bone strength estimated for different conditions and ages. The development of new techniques for measuring BMD has focused much of the recent research in the clinical setting, but the mechanical aspects have not been adequately studied [13]-[16]. In other cases, the improvements have been applied on statistical models previously [18] [19]. Only in one published paper [17] a new method derived from DXA measures was developed for bone strength assessment.

Concerning the finite element simulation, and based on previous micromechanical models [20], various methods have been developed, but they are difficult to extrapolate to the scale required to get realistic predictions from different approaches [21] [22]. The incorporation of the latest imaging techniques (QCT) and BMD measurement (DXA) [24] [27]-[29] has allowed the improvement of these models. However, most models use standard yield criteria for estimating the risk of fracture [27] [28], without considering essential aspects in fracture analysis. Nonetheless, all models assume that bone mineral density is the basic measurement, and it should therefore be used as a benchmark in predicting fracture risk.

From the mechanical point of view, the exposition of the bone to cyclic loads of high value in a damaged bone, once the degenerative process is started, decreases its strength over the time and produces a cumulative damage which can lead to a final fracture. It seems apparent that Damage Mechanics and Fracture Mechanics criteria should be incorporated in any model intending to obtain reliable results. In this regard, our model combines all these requirements, and might be useful as a basis for future more sophisticated models.

Moreover, this model enables to incorporate future developments with the same methodology. In the first term, a more accurate bone density distribution by individual elements in the mesh could be used. That requires a planned collection of BMD data, by means of DXA or CT scan images. More complex damage models can be added, including mechanical behavior of anisotropic or mixed models, based on both deformations and tensions. It would also be possible to include crack growth models fitting to the results of in vitro bone fracture. Finally, a parametric finite element model of the femoral head could be performed including both the loads produced on the bone and the shape and dimensions of a specific patient.

Despite DXA measurements just quantify bone mass and not bone quality, it is widely accepted as a macroscopic indicator of bone strength and stiffness and also that micro-fractures exert an important influence on the mechanical strength of the bone. Finally, clinical trials are needed to validate the proposed model in order to apply it to the clinical practice helping for treatment decisions.

\section{Conclusion}

A mechanical model based on Damage and Fracture Mechanics and DXA measurements, for predicting the probability of fracture in osteoporotic patients has been carried out. The model represents a first step towards the development of new tools for diagnosis and prevention of osteoporosis. The incorporation of clinical measurements and simulation results will be useful for an individualized monitoring and treatment in specific patients. 


\section{Acknowledgements}

This work has been partially financed through the research project "Development and Clinical Application of a Mechanical Model for the Analysis of Spine Fractures due to Low Energy Trauma, based on Bone Mineral Density Measurements”, supported by Mutua Madrileña Foundation.

\section{Competing Interests}

The authors declare that they have no conflict of interest.

\section{Authors' Contributions}

AH and LG conceived the approach of this work. EL and LG conceived and developed the predictive model for fracture probability. AH, ALE and JM contribute with clinical measurements and experience with osteoporotic patients. EL, EI and SP conceived and developed the finite element model and carried out all the simulations. AH and LG coordinated the work between surgeons and engineers. All authors participated in the drawing up of the manuscript, and read and approved the final manuscript.

\section{References}

[1] National Osteoporosis Foundation (2010) Clinician’s Guide to Prevention and Treatment of Osteoporosis. National Osteoporosis Foundation, Washington DC.

[2] Johnell, O. and Kanis, J. (2005) Epidemiology of Osteoporotic Fractures. Osteoporosis International, 16, S3-S7. http://dx.doi.org/10.1007/s00198-004-1702-6

[3] Cooper, C., O’Neill, T. and Silman A. (1993) The Epidemiology of Vertebral Fractures. Bone, 14, S89-S97. http://dx.doi.org/10.1016/8756-3282(93)90358-H

[4] Wasnich, R.D. (1996) Vertebral Fracture Epidemiology. Bone, 18, S179-S183. http://dx.doi.org/10.1016/8756-3282(95)00499-8

[5] Nevitt, M.C., Ettinger, B., Black, D.M., Stone, K., Jamal, S.A., Ensrud, K., Segal, M., Genant, H.K. and Cummings, S.R. (1998) The Association of Radiographically Detected Vertebral Fractures with Back Pain and Function: A Prospective Study. Annals of Internal Medicine, 128, 793-800. http://dx.doi.org/10.7326/0003-4819-128-10-199805150-00001

[6] Kado, D.M., Browner, W.S., Palermo, L., Nevitt, M.C., Genant, H.K. and Cummings, S.R. (1999) Vertebral Fractures and Mortality in Older Women. Archives of Internal Medicine, 159, 1215-1220. http://dx.doi.org/10.1001/archinte.159.11.1215

[7] Kaptoge, S., Armbrecht, G., Felsenberg, D., Lunt, M., O’Neill, T.W., Silman, A.J. and Reeve, J. (EPOS Study Group) (2004) When Should the Doctor Order a Spine X-Ray? Identifying Vertebral Fractures for Osteoporosis Care: Results from the European Prospective Osteoporosis Study (EPOS). Journal of Bone and Mineral Research, 19, 1982-1993. http://dx.doi.org/10.1359/jbmr.040901

[8] Delmas, P.D., van de Langerijt, L., Watts, N.B., Eastell, R., Genant, H., Grauer, A. and Cahall, D.L. (IMPACT Study Group) (2005) Underdiagnosis of Vertebral Fractures Is a Worldwide Problem: The IMPACT Study. Journal of Bone and Mineral Research, 20, 557-563. http://dx.doi.org/10.1359/JBMR.041214

[9] Ross, P.D. (1997) Clinical Consequences of Vertebral Fractures. American Journal of Medicine, 103, S30-S40. http://dx.doi.org/10.1016/S0002-9343(97)90025-5

[10] Kaptoge, S., Armbrecht, G., Felsenberg, D., Lunt, M., Weber, K., Boonen, S., Jajic, I.., Stepan, J.J., Banzer, D., Reisinger, W., Janott, J., Kragl, G., Scheidt-Nave, C., Felsch, B., Matthis, C., Raspe, H.H., Lyritis, G., Póor, G., Nuti, R., Miazgowski, T., Hoszowski, K., Armas, J.B., Vaz, A.L., Benevolenskaya, L.I., Masaryk, P., Cannata, J.B., Johnell, O., Reid, D.M., Bhalla, A., Woolf, A.D., Todd, C.J., Cooper, C., Eastell, R., Kanis, J.A., O’Neill, T.W., Silman, A.J. and Reeve, J. (2006) Whom to Treat? The Contribution of Vertebral X-Rays to Risk-Based Algorithms for Fracture Prediction. Results from the European Prospective Osteoporosis Study. Osteoporosis International, 17, 1369-1381. http://dx.doi.org/10.1007/s00198-005-0067-9

[11] Ismail, A.A., Cockerill, W., Cooper, C., Finn, J.D., Abendroth, K., Parisi, G., Banzer, D., Benevolenskaya, L.I., Bhalla, A.K., Armas, J.B., Cannata, J.B., Delmas, P.D., Dequeker, J., Dilsen, G., Eastell, R., Ershova, O., Falch, J.A., Felsch, B., Havelka, S., Hoszowski, K., Jajic, I., Kragl, U., Johnell, O., López Vaz, A., Lorenc, R., Lyritis, G., Marchand, F., Masaryk, P., Matthis, C., Miazgowski, T., Pols, H.A., Poor, G., Rapado, A., Raspe, H.H., Reid, D.M., Reisinger, W., Janott, J., Scheidt-Nave, C., Stepan, J., Todd, C., Weber, K., Woolf, A.D., Ambrecht, G., Gowin, W., Felsenberg, D., Lunt, M., Kanis, J.A., Reeve, J., Silman, A.J. and O’Neill, T.W. (2001) Prevalent Vertebral Deformity Predicts 
Incident Hip though Not Distal Forearm Fracture: Results from European Prospective Osteoporosis Study. Osteporosis International, 12, 85-90. http://dx.doi.org/10.1007/s001980170138

[12] Lindsay, R., Silverman, S.L., Cooper, C., Hanley, D.A., Barton, I., Broy, S.B., Licata, A., Benhamou, L., Geusens, P., Flowers, K., Stracke, H. and Seeman, E. (2001) Risk of New Vertebral Fracture in the Year Following a Fracture. The Journal of the American Medical Association, 285, 320-323. http://dx.doi.org/10.1001/jama.285.3.320

[13] Delmas, P.D., Genant, H.K., Crans, G.G., Stock, J.L., Wong, M., Siris, E. and Adachi, J.D. (2003) Severity of Prevalent Vertebral Fractures and the Risk of Subsequent Vertebral and Nonvertebral Fractures: Results from the MORE Trial. Bone, 33, 522-532. http://dx.doi.org/10.1016/S8756-3282(03)00241-2

[14] Christiansen, B.A. and Bouxsein, M.L. (2010) Biomechanics of Vertebral Fractures and the Vertebral Fracture Cascade. Current Osteoporosis Reports, 8, 198-204. http://dx.doi.org/10.1007/s11914-010-0031-2

[15] Wustrack, R., Seeman, E., Bucci-Rechtweg, C., Burch, S., Palermo, L. and Black, D.M. (2012) Predictors of New and Severe Vertebral Fractures: Results from the HORIZON Pivotal Fracture Trial. Osteoporosis International, 23, 53-58. http://dx.doi.org/10.1007/s00198-011-1664-4

[16] Briggs, A.M., Wrigley, T.V., van Dieën, J.H., Phillips, B., Lo, S.K., Greig, A.M. and Bennell, K.L. (2006) The Effect of Osteoporotic Vertebral Fracture on Predicted Spinal Loads in Vivo. European Spine Journal, 15, 1785-1795. http://dx.doi.org/10.1007/s00586-006-0158-0

[17] Kanis, J.A., Borgstrom, F., De Laet, C., Johansson, H., Johnell, O., Jonsson, B., Oden, A., Zethraeus, N., Pfleger, B. and Khaltaev, N. (2005) Assessment of Fracture Risk. Osteoporosis International, 16, 581-589. http://dx.doi.org/10.1007/s00198-004-1780-5

[18] Kanis, J.A., Black, D., Cooper, C., Dargent, P., Dawson-Hughes, B., De Laet, C., Delmas, P., Eisman, J., Johnell, O., Johnsson, B., Melton, L., Oden, A., Papapoulos, S., Pols, H., Rizzoli, R., Silman, A. and Tenenhouse, A. (2002) A New Approach to the Development of Assessment Guidelines for Osteoporosis. Osteoporosis International, 13, 527536. http://dx.doi.org/10.1007/s001980200069

[19] Kanis, J.A., Oden, A., Johnell, O., De Laet, C., Brown, J., Burckhardt, P., Cooper, C., Christiensen, C., Cummings, S., Eisman, J.A., Fujiwara, S., Glüer, C., Goltzman, D., Hans, D., Krieg, M.A., La Croix, A., McCloskey, E., Mellstrom, D., Melton, L.J., Pols, H., Reeve, J., Sanders, K., Schott, A.M., Silman, A., Torgerson, D., van Staa, T, Watts, N.B. and Yoshimura, N. (2007) The Use of Clinical Risk Factors Enhances the Performance of BMD in the Prediction of Hip and Osteoporotic Fractures in Men and Women. Osteoporosis International, 18, 1033-1046. http://dx.doi.org/10.1007/s00198-007-0343-y

[20] Kanis, J.A., Johnell, O., Oden, A., Johansson, E. and McCloskey, E. (2008) FRAX ${ }^{\mathrm{TM}}$ and the Assessment of Fracture Probability in Men and Women from the UK. Osteoporosis International, 19, 385-397. http://dx.doi.org/10.1007/s00198-007-0543-5

[21] Van Geel, T.A., van den Bergh, J.P., Dinant, G.J. and Geusens, P.P. (2010) Individualizing Fracture Risk Prediction. Maturitas, 65, 143-148. http://dx.doi.org/10.1016/j.maturitas.2009.12.007

[22] Ensrud, K.E., Lui, L.Y., Taylor, B.C., Schousboe, J.T., Donaldson, M.G., Fink, H.A., Cauley, J.A., Hillier, T.A., Browner, W.S. and Cummings, S.R. (2009) A Comparison of Prediction Models for Fractures in Older Women: Is More Better? Archives of Internal Medicine, 169, 2087-2094. http://dx.doi.org/10.1001/archinternmed.2009.404

[23] Moayyeri, A., Kaptoge, S., Dalzell, N., Bingham, S., Luben, R.N., Wareham, N.J., Reeve, J. and Khaw, K.T. (2009) Is QUS or DXA Better for Predicting the 10-Year Absolute Risk of Fracture? Journal of Bone and Mineral Research, 24, 1319-1325. http://dx.doi.org/10.1359/jbmr.090212

[24] Langsetmo, L., Leslie, W.D., Zhou, W., Goltzman, D., Kovacs, C.S., Prior, J., Josse, R., Olszynski, W.P., Davison, K. S., Anastassiades, T., Towheed, T., Hanley, D.A., Kaiser, S. and Kreiger, N. (2010) Using the Same Bone Density Reference Database for Men and Women Provides a Simpler Estimation of Fracture Risk. Journal of Bone and Mineral Research, 25, 2108-2114. http://dx.doi.org/10.1002/jbmr.112

[25] Boehm, H.F., Horng, A., Notohamiprodjo, M., Eckstein, F., Burklein, D., Panteleon, A., Lutz, J. and Reiser, M. (2008) Prediction of the Fracture Load of Whole Proximal Femur Specimens by Topological Analysis of the Mineral Distribution in DXA-Scan Images. Bone, 43, 826-831. http://dx.doi.org/10.1016/j.bone.2008.07.244

[26] Schechner, Z., Luo, G., Kaufman, J.J. and Siffert, R.S. (2010) A Poisson Process Model for Hip Fracture Risk. Medical \& Biological Engineering \& Computing, 48, 799-810. http://dx.doi.org/10.1007/s11517-010-0638-6

[27] Baker-LePain, J.C., Luker, K.R., Lynch, J.A., Parimi, N., Nevitt, M.C. and Lane, N.E. (2011) Active Shape Modeling of the Hip in the Prediction of Incident Hip Fracture. Journal of Bone and Mineral Research, 26, 468-474. http://dx.doi.org/10.1002/jbmr.254

[28] Lee, T.C., McHugh, P.E., O’Brien, F.J., O’Mahoney, D., Taylor, D., Bruzzi, M., Rackard, S.M., Kennedy, O.D., Mahony, N.J., Harrison, N., Lohfield, S., Brennan, O., Gleeson, J., Hazenberg, J.G., Mullins, L., Tyndyk, M., McNamara, L.M., O’Kelly, K.U. and Prendergast, P.J. (2004) Bone for Life: Osteoporosis, Bone Remodelling and Computer Simulation. In: Prendergast, P.J. and McHugh, P.E., Eds., Topics in Bio-Mechanical Engineering, Trinity Centre for Bio- 
Engineering \& National Centre for Biomedical Engineering Science, Dublin, 58-93.

[29] Boccaccio, A., Vena, P., Gastaldi, D., Franzoso, G., Pietrabissa, R. and Pappalettere, C. (2008) Finite Element Analysis of Cancellous Bone Failure in the Vertebral Body of Healthy and Osteoporotic Subjects. Proceedings of the Institution of Mechanical Engineers, Part H: Journal of Engineering in Medicine, 222, 1023-1036. http://dx.doi.org/10.1243/09544119JEIM296

[30] Zhang, L., Yang, G., Wu, L. and Yu, B. (2010) The Biomechanical Effects of Osteoporosis Vertebral Augmentation with Cancellous Bone Granules or Bone Cement on Treated and Adjacent Non-Treated Vertebral Bodies: A Finite Element Evaluation. Clinical Biomechanics, 25, 166-172. http://dx.doi.org/10.1016/j.clinbiomech.2009.10.006

[31] MacNeil, J.A., Adachi, J.D., Goltzman, D., Josse, R.G., Kovacs, C.S., Prior, J.C., Olszynski, W., Davison, K.S. and Kaiser, S.M. (2011) Predicting Fracture Using 2D Finite Element Modelling. Medical Engineering \& Physics, 34, 478484. http://dx.doi.org/10.1016/j.medengphy.2011.08.008

[32] Kaneko, M., Ohnishi, I., Bessho, M., Matsumoto, T., Ohashi, S., Tobita, K. and Nakamura, K. (2011) Prediction of Proximal Femur Strength by a Quantitative Computed Tomography-Based Finite Element Method-Creation of Predicted Strength Data of the Proximal Femur According to Age Range in a Normal Population and Analysis of Risk Factors for Hip Fracture. The Journal of Bone \& Joint Surgery (British Volume), 93B, 216.

[33] Bryan, R., Nair, P.B. and Taylor, M. (2009) Use of a Statistical Model of the Whole Femur in a Large Scale, MultiModel Study of Femoral Neck Fracture Risk. Journal of Biomechanics, 42, 2171-2176. http://dx.doi.org/10.1016/j.jbiomech.2009.05.038

[34] Bessho, M., Ohnish, I., Matsumoto, T., Ohashi, S., Matsuyama, J., Tobita, K., Kaneko, M. and Nakamura, K. (2009) Prediction of Proximal Femur Strength Using a CT-Based Nonlinear Finite Element Method: Differences in Predicted Fracture Load and Site with Changing Load and Boundary Conditions. Bone, 45, 226-231. http://dx.doi.org/10.1016/j.bone.2009.04.241

[35] Derikx, L.C., Vis, R., Meinders, T., Verdonschot, N. and Tanck, E. (2011) Implementation of Asymmetric Yielding in Case-Specific Finite Element Models Improves the Prediction of Femoral Fractures. Computer Methods in Biomechanics and Biomedical Engineering, 14, 183-193. http://dx.doi.org/10.1080/10255842.2010.542463

[36] Tellache, M., Pithioux, M., Chabrand, P. and Hochard, C. (2009) Femoral Neck Fracture Prediction by Anisotropic Yield Criteria. European Journal of Computational Mechanics, 18, 33-41.

[37] Amin, S., Kopperdhal, D.L., Melton 3rd, L.J., Achenbach, S.J., Therneau, T.M., Riggs, B.L., Keaveny, T.M. and Khosla, S. (2011) Association of Hip Strength Estimates by Finite-Element Analysis with Fractures in Women and Men. Journal of Bone and Mineral Research, 26, 1593-1600. http://dx.doi.org/10.1002/jbmr.347

[38] Keaveny, T.M., Hoffmann, P.F., Singh, M., Palermo, L., Bilezikian, J.P., Greenspan, S.L. and Balck, D.M. (2008) Femoral Bone Strength and Its Relation to Cortical and Trabecular Changes after Treatment with PTH, Alendronate, and Their Combination as Assessed by Finite Element Analysis of Quantitative CT Scans. Journal of Bone and Mineral Research, 23, 1974-1982. http://dx.doi.org/10.1359/jbmr.080805

[39] Carter, D.R. and Hayes, W.C. (1977) The Compressive Behavior of Bone as a Two-Phase Porous Structure. The Journal of Bone and Joint Surgery, 59, 954-962.

[40] López, E., Ibarz, E., Herrera, A., Mateo, J., Lobo-Escolar, A., Puértolas, S. and Gracia, L. (2012) A Mechanical Model for Predicting the Probability of Osteoporotic Hip Fractures Based in DXA Measurements and Finite Element Simulation. Biomedical Engineering Online, 11, 84. http://dx.doi.org/10.1186/1475-925X-11-84

[41] Ste-Marie, L.G., Sod, E., Johnson, T. and Chines, A. (2004) Five Years of Treatment with Risedronate and Its Effects on Bone Safety in Women with Postmenopausal Osteoporosis. Calcified Tissue International, 75, 469-476. http://dx.doi.org/10.1007/s00223-004-0039-7

[42] Cummings, S.R., San Martin, J., McClung, M.R., Siris, E.S., Eastell, R., Reid, I.R., Delmas, P., Zoog, H.B., Austin, M., Wang, A., Kutilek, S., Adami, S., Zanchetta, J., Libanati, C., Siddhanti, S. and Christiansen, C. (2009) Denosumab for Prevention of Fractures in Postmenopausal Women with Osteoporosis. The New England Journal Medicine, 361, 756765. http://dx.doi.org/10.1056/NEJMoa0809493

[43] Harris, S.T., Watts, N.B., Genant, H.K., McKeever, C.D., Hangartner, T., Keller, M., Chesnut 3rd, C.H., Brown, J., Eriksen, E.F., Hoseyni, M.S., Axelrod, D.W. and Miller, P.D. (1999) Effects of Risedronate Treatment on Vertebral and Nonvertebral Fractures in Women with Postmenopausal Osteoporosis: A Randomized Controlled Trial. Vertebral Efficacy with Risedronate Therapy (VERT) Study Group. The Journal of American Medical Association, 282, 13441352. http://dx.doi.org/10.1001/jama.282.14.1344

[44] Reginster, J., Minne, H.W., Sorensen, O.H., Hooper, M., Roux, C., Brandi, M.L., Lund, B., Ethgen, D., Pack, S., Roumagnac, I. and Eastell, R. (2000) Randomized Trial of the Effects of Risedronate on Vertebral Fractures in Women with Established Postmenopausal Osteoporosis. Vertebral Efficacy with Risedronate Therapy (VERT) Study Group. Osteoporosis International, 11, 83-91. http://dx.doi.org/10.1007/s001980050010 
[45] McClung, M.R., Geusens, P., Miller, P.D., Zippel, H., Bensen, W.G., Roux, C., Adami, S., Fogelman, I., Diamond, T., Eastell, R., Meunier, P.J. and Reginster, J.Y. (Hip Intervention Program Study Group) (2001) Effect of Risedronate on the Risk of Hip Fracture in Elderly Women. The New England Journal Medicine, 344, 333-339. http://dx.doi.org/10.1056/NEJM200102013440503

[46] Papapoulos, S., Chapurlat, R., Libanati, C., Brandi, M.L., Brown, J.P., Czerwiński, E., Krieg, M.A., Man, Z., Mellström, D., Radominski, S.C., Reginster, J.Y., Resch, H., Ivorra, J.A.R., Roux, C., Vittinghoff, E., Austin, M., Daizadeh, N., Bradley, M.N., Grauer, A., Cummings, S.R. and Bone, H.G. (2012) Five Years of Denosumab Exposure in Women with Postmenopausal Osteoporosis: Results from the First Two Years of the FREEDOM Extension. Journal of Bone and Mineral Research, 27, 694-701. http://dx.doi.org/10.1002/jbmr.1479

[47] Mazess, R.B. and Barden, H. (1999) Bone Density of the Spine and Femur in Adult White Females. Calcified Tissue International, 65, 91-99. http://dx.doi.org/10.1007/s002239900663

[48] López, E., Herrera, A. and Gracia, L. (2011) Diseño y desarrollo de un modelo de predicción de fracturas osteoporóticas: Aplicación al Cuello Femoral y a la Columna Lumbar (in Spanish). Lambert Academic Publishing, Saarbrücken.

[49] Kargarnovin, M.H., Bagher-Ebrahimi, M. and Katoozian, H.R. (2006) Damage Initiation and Growth in a Long Bone under Increasing Monotonic Loading Using the Continuum Damage Mechanics Principle. Proceedings of the 5th International Conference on Engineering Computational Technology, Las Palmas de Gran Canaria, 12-15 September 2006, Paper 191. http://dx.doi.org/10.4203/ccp.84.191

[50] Paris, P. and Erdogan, F. (1963) A Critical Analysis of Crack Propagation Laws. Journal of Fluids Engineering, 85, 528-534. http://dx.doi.org/10.1115/1.3656900

[51] Taylor, D. (1998) Microcrack Growth Parameters for Compact Bone Deduced from Stiffness Variations. Journal of Biomechanics, 31, 587-592. http://dx.doi.org/10.1016/S0021-9290(98)00050-5

[52] Ibarz, E., Herrera, A., Más, Y., Rodríguez-Vela, J., Cegoñino, J., Puértolas, S. and Gracia, L. (2012) Development and Kinematic Verification of a Finite Element Model for the Lumbar Spine: Application to Disc Degeneration. BioMed Research International, 2013, 705185.

[53] SIEMENS. http://www.plm.automation.siemens.com

[54] White, A.A. and Panjabi, M.M. (1990) Clinical Biomechanics of the Spine. 2nd Edition, Lippincott Williams and Wilkins, Philadelphia.

[55] Kapandji, I.A. (2008) The Physiology of the Joints. 6th Edition, Volume III, Churchill Livingstone, New York.

[56] Denozière, G. and Ku, D.N. (2006) Biomechanical Comparison between Fusion of Two Vertebrae and Implantation of an Artificial Intervertebral Disc. Journal of Biomechanics, 39, 766-775. http://dx.doi.org/10.1016/j.jbiomech.2004.07.039

[57] Dassault Systèmes. http://www.3ds.com/

[58] Pitzen, T., Geisler, F., Matthis, D., Müller-Storz, H., Barbier, D., Steudel, W.I. and Feldges, A. (2002) A Finite Element Model for Predicting the Biomechanical Behaviour of the Human Lumbar Spine. Control Engineering Practice, 10, 83-90. http://dx.doi.org/10.1016/S0967-0661(01)00129-0

[59] Rohlmann, A., Bauer, L., Zander, T., Bergmann, G. and Wilke, H.J. (2006) Determination of Trunk Muscle Forces for Flexion and Extension by Using a Validated Finite Element Model of the Lumbar Spine and Measured in Vivo Data. Journal of Biomechanics, 39, 981-989. http://dx.doi.org/10.1016/j.jbiomech.2005.02.019

[60] Nasto, L.A., Fusco, A., Colangelo, D., Mormando, M., Di Giacomo, G., Rossi, B., De Marinis, L., Logroscino, C.A. and Pola, E. (2012) Clinical Predictors of Vertebral Osteoporotic Fractures in Post-Menopausal Women: A Cross-Sectional Analysis. European Review Medical Pharmacological Science, 16, 1227-1234.

[61] Dall'Ara, E., Pahr, D., Varga, P., Kainberger, F. and Zysset, P. (2012) QCT-Based Finite Element Models Predict Human Vertebral Strength in Vitro Significantly Better than Simulated DEXA. Osteoporosis International, 23, 563-572. http://dx.doi.org/10.1007/s00198-011-1568-3

[62] Imai, K., Ohnishi, I., Bessho, M. and Nakamura, K. (2006) Nonlinear Finite Element Model Predicts Vertebral Bone Strength and Fracture Site. Spine (Phila Pa 1976), 31, 1789-1794.

[63] Sisodia, G.B. (2013) Methods of Predicting Vertebral Body Fractures of the Lumbar Spine. World Journal Orthopaedics, 4, 241-247. http://dx.doi.org/10.5312/wjo.v4.i4.241 


\section{List of Abbreviations}

BMD: Bone Mineral Density

CT: Computed Tomography

DXA: Dual-energy X-ray Absorptiometry

FE: Finite Elements

FRAX: Fracture Risk Assessment Tool

PTH: Parathyroid Hormone

QCT: Quantitative Computed Tomography

WHO: World Health Organization 